\title{
Subjetividad y aprendizaje en los límites de la novela educativa. Una mirada sobre En busca del tiempo perdido, de Marcel Proust.
}

Alejandro A. Cerletti

\section{Presentación}

No es inusual que En busca del tiempo perdido (PROUST, 1990/1996) sea considerada, de una manera amplia, dentro de las "novelas de formación" o "educativas". Este tipo de caracterización no suele ser ingenua, ya que supone no sólo una eventual definición de género sino también una orientación de lectura o una preconcepción de análisis. En este trabajo voy a sostener que la obra mayor de Proust puede ser pensada como consumación y, a la vez, como quiebre de aquella forma de definirla. En consecuencia, se llevará adelante un pasaje del sentido más o menos clásico que suele atribuírsele dentro de las novelas educativas hacia las condiciones de su acabamiento o ruptura. Este desplazamiento permitirá pensar la cuestión de la constitución de la subjetividad desde un punto de vista diferente.

\section{Sobre el sentido educativo de En busca del tiempo perdido}

Si quisiéramos recortar algunos rasgos específicos de lo que se ha entendido tradicionalmente como novela de educación o formación deberíamos señalar al menos dos características distintivas. Por un lado, la novela educativa es tributaria del ciclo: extrañeza / aprendizaje / autoconocimiento o autodescubrimiento / integración al mundo; por otro, presupone una "naturaleza" humana o un conjunto de disposiciones preexistentes en los seres humanos que deberán ir tomando forma, o conformándose, de acuerdo con las pautas dominantes de una cultura. Como es sabido, estas características tienen su origen en la tradición romántica y humanística, que ha hecho de la idea de "formación" el eje principal de la integración comunitaria. Voy a llamar esquema lineal a la primera característica y esquema metafísico, a la segunda. El primero define un recorrido; el segundo, una esencia. En busca del tiempo perdido desborda el esquema lineal y quiebra el esquema metafísico. El nudo de este movimiento, que reformula por completo el sentido educativo de la obra, se halla, en las páginas finales del último tomo de En busca del tiempo perdido, en El tiempo recobrado, específicamente, en la visita del héroe al hotel de Guermantes, verdadera clave de bóveda de lo que llamaremos el acontecimiento Proust.

\section{Entre el héroe-narrador y el autor. El acontecimiento Proust}

Diversas líneas críticas han establecido un paralelo entre la vida de Proust y En busca del tiempo perdido. Por lo general, se han esmerado en tratar de reconocer en la novela a ciertos personajes o lugares reales que habrían servido a Proust de inspiración o modelo. Si bien esta mirada biográfica sobre la obra aporta datos significativos para comprender el contexto de su producción e iluminar algunas interpretaciones, no me voy a referir precisamente a esto (1). Lo que me interesa 
remarcar -y esta será mi primera hipótesis- es más bien lo siguiente: tanto en la novela como en la vida de Proust es posible reconocer un momento en el que se produce un quiebre o una ruptura radical con el estado de cosas que permitía, hasta entonces, construir un sentido y definir una continuidad. Esto es: lo que se sabía hasta ahí no es más capaz de dar cuenta de lo que sucede luego. Lo que deviene es una construcción novedosa fruto de una decisión (en este caso, artística) sobre algunos sucesos aleatorios. La segunda hipótesis (complementaria de la primera) que guiará este trabajo es que el tipo de ruptura y la consecuente decisión de qué hacer a partir de ella son del mismo tenor, tanto en la novela como en la vida de Proust. A este punto en común (muy diferente de la referencia autobiográfica) entre vida y obra lo llamaré "acontecimiento Proust" y podría sintetizarse en una expresión: la obra de arte (re)hace el tiempo (2).

La decisión de escribir, que recompondrá todo un trayecto anterior, anuncia el final de una secuencia temporal en un libro (expresa el momento consciente de un acabamiento: la parte final de El tiempo recobrado y el temor del héroe de no tener tiempo de vida para concluir la obra por venir) y en una vida (la lucha del propio Proust por concluir su obra antes de morir), y, a su vez, el comienzo de una nueva dimensión temporal: la que inaugura la obra literaria. Pero a lo largo de la obra, el punto central en el mantenimiento de una secuencia temporal se juega en qué hacer frente a la irrupción desestructurante del azar. La aparición del azar en la obra toma la forma del recuerdo involuntario y es la muestra de que el tiempo puede ser otra cosa que un indefectible trayecto hacia la muerte. ¿Qué puede ocurrir, entonces, para que estos sucesos aleatorios no sean más que una presencia fugaz del pasado? ¿Cómo podrán servir para recobrar ese pasado eternizándolo en un presente permanente?

Para Ricour, la cuestión es determinar el tipo de relación que puede plantearse entre aquellos momentos felices que han ofrecido al héroe el azar y la memoria involuntaria, y la "historia invisible de una vocación", final del trayecto de la novela (RICCEUR, 1998, p. 603). Ricœur destaca (es una de sus hipótesis) que la relación sobre la que se intenta recuperar el tiempo a escala global en En busca del tiempo perdido bien podría estar basada o deducida de las experiencias canónicas puntuales de reminiscencia que se van presentando a lo largo del libro. Para ello resalta el papel fundamental que le cabe a algunas figuras de estilo cuya función es expresar la relación entre objetos diferentes. La clave de esta figuración es, según Ricoeur, la metáfora: "esta relación metafórica, esclarecida por la elucidación de los momentos dichosos, se convierte en la matriz de todas las relaciones a que dos objetos distintos, pese a su diferencia, son elevados a la esencia y sustraídos a las contingencias del tiempo. (...) El tiempo recobrado es (...) el tiempo perdido eternizado por la metáfora" (RICCEUR, 1998, p. 611). Para Ricour, entonces, la cuestión se definiría cuando se llega a las "esencias" eternas a través de las metáforas, burlándose de este modo la caducidad del tiempo.

A los efectos de la propuesta que estoy llevando adelante, no nos interesará tanto detenernos en la necesidad de encontrar los recursos estilísticos que puedan servir como nexo entre el pasado del héroe y el presente de un futuro escritor, sino más bien ver las consecuencias que es posible extraer de la decisión que supone 
considerar que la obra de arte es capaz de (re)hacer el tiempo. Esta decisión es fundamental para el sentido del relato pero también, y en especial, para Proust (que fue quien escribió finalmente la obra que hoy podemos leer). No se tratará tampoco de describir meramente el sentimiento emocionante que puede provocar el vínculo fortuito de dos impresiones separadas en el tiempo. Revivir con intensidad un momento, como un fulgor del pasado que irrumpe sorpresivamente en el hoy, es sólo una advertencia de que es posible vislumbrar, de una manera inédita, alguna secuencia del pasado. El desafío mayor que acomete Proust es llevar hasta sus últimas consecuencias el pensar aquel vínculo dentro de una recomposición total del tiempo por obra de la producción artística. La materialidad (la impresión) de la experiencia singular presente (el sabor de una magdalena humedecida en una infusión, el sonido de una campanilla, la textura de una servilleta), que permite actualizar el pasado con la intensidad del aquí y ahora, no encuentra contrapartida en ninguna repetición voluntaria (ningún esfuerzo consciente de memoria), que sólo sirve para construir una imagen pálida y distorsionada de la experiencia originaria. En efecto, el recuerdo involuntario abre un camino privilegiado hacia el pasado, pero para transformar ese instante nostálgico en una eternidad deberá operar ahí la intervención artística del escritor. El recuerdo involuntario es la irrupción del azar: el sabor de la magdalena en el presente difuso de la narración que trae, en un fulgor, la magdalena de tante Léonie, pero es la obra de arte la que trae al pueblo de la infancia, Combray, en toda su magnitud, y esto, más que un esfuerzo de la memoria voluntaria, es el esfuerzo del escritor en su creación (3).

Dijimos que la visita al hotel de Guermantes (y en especial la secuencia de la pequeña biblioteca) establece el momento crucial que permite plantear una nueva mirada sobre el tiempo. Todo el remate de El tiempo recobrado da cuenta de que un acontecimiento, la decisión de escribir, sostenida en que el arte puede fundar otro tiempo, permite constituir, a su vez, una subjetividad. Y esta subjetividad será desplegada en la medida en que el héroe-narrador sea consecuente y esté a la altura de aquella decisión. La fidelidad a ese momento inaugural propondrá una relación temporal propia de la dialéctica del ser y el acontecimiento, que hará visibles ciertas cosas y otras no. Esto quiere decir que sólo a la luz del acontecimiento Proust podremos comprender en su real magnitud los diversos pasajes en que el recuerdo involuntario produjo un quiebre azaroso en la continuidad normal de un relato o una vida. Los sucesos de la magdalena, las losas desiguales o la rugosidad de una servilleta recién alcanzan su dimensión completa cuando comprendemos que son las experiencias puntuales o las localizaciones de un acontecimiento mayor que las hace existir.

Es significativo el contraste que plantea la novela entre la pereza del héroe en decidirse a comenzar a escribir y el esfuerzo que supone sostenerse en la escritura. Por cierto, la contraposición realza el efecto. Es otro contacto con la decisión de Proust de escribir En busca del tiempo perdido: su tiempo (un tiempo en que el día y la noche se disolvieron, en una habitación casi aislada del mundo) se transformó de una manera tal a la luz de su apuesta artística que su propia vida se consumió en la fidelidad a esa decisión. La obsesiva perseverancia de Proust por terminar la obra apuntaba, mucho más que a no dejar inconclusa una novela, a 
poder desplegar la totalidad de las consecuencias que pudieran extraerse de su apuesta vital, ya que esto implicaba (re)construir el tiempo, nada menos, para poder así "recobrarlo".

La experiencia de la escritura transfigura dos vidas: la del escritor-autor y la del narrador-héroe del relato. Hay un sujeto Proust y otro por constituirse. Lo magnífico de la obra de Proust es que este último involucra al lector.

\section{Por el camino de la interpretación de los signos (hermenéutica)}

Para Deleuze, En busca del tiempo perdido , mucho más que una exposición sobre la memoria, es la narración de un aprendizaje. Y "aprender concierne esencialmente a los signos (...). Aprender es, en primer lugar, considerar una materia, un objeto, un ser, como si emitieran signos por descifrar, por interpretar." (DELEUZE, 1995, p.12). Todo acto de aprender es entonces una interpretación de signos. La obra de Proust desplegará diversas líneas de aprendizaje de signos. El conjunto de la obra constituirá, para Deleuze, un recorrido de "formación" en la que el héroe será el descifrador o el intérprete del nutrido panorama de jeroglíficos que se le van presentando.

Esta mirada sobre En busca del tiempo perdido, que incorpora elementos de análisis valiosos y sugerentes, se expande en los límites de un riesgo: intentar leer En busca del tiempo perdido como una suerte de desocultamiento de una esencia (de lo "verdadero"), o una clave, que estaría oculta y que una vez que se la puede abordar daría sentido a todo; y es un riesgo porque supone la esencialización de un ya hay algo ahí, pero no está visible, y de lo que se trataría es de ir descubriéndolo. Si queremos mantener la lectura deleuziana de Proust (de la que Ricour se hace eco) del aprendizaje de signos, y hacerla coherente con lo que hemos planteado, deberíamos suponer que el aprendizaje es más bien la manera de situarse en un mundo novedoso, que es consecuencia de una apuesta sobre donde no había otra cosa. Este aprendizaje entonces es un autoaprendizaje en la capacidad de extraer consecuencias de la decisión inicial (la resignificación del recuerdo involuntario, la apropiación productiva del azar). Lo "recuperado" es, en fin, la vida.

Recordemos que las peripecias del héroe (el recorrido lineal que va, de la mano del narrador, desde Combray hasta el hotel de Guermantes) condujeron a su fracaso en la integración al mundo. Es notable la descripción de esta decadencia que hace Proust a través de los rostros transfigurados, en el fantasmal baile de máscaras. El tiempo operó en una dirección: la de la implacable destrucción de cuerpos y espíritus. El héroe queda expuesto a un dolorosos naufragio en el viaje de aprendizaje de los signos. Para Ricœur esto se debía a que los signos estaban privados de un principio que los pudiera hacer comprender (RICCEUR, 1998, p. 603)(4). Pero más que faltarles la llave de una interpretación la obra nos muestra que estaban puestos allí, mucho más que para ser comprendidos, para ser reinventados. Este planteo, en definitiva, no se aleja demasiado de la idea de Deleuze: "La obra de arte no se limita a interpretar o a emitir signos por interpretar; los produce mediante procedimientos determinables." (DELEUZE, 1995, p.7). À la recherche du temps perdu es una búsqueda (recherche) que es fundamentalmente 
una invención (artística). Se trata del mismo gesto creador que podría corresponder al investigador científico cuyo descubrimiento es, en realidad, más que un

desocultamiento, una invención producto de su investigación (recherche). En busca del tiempo perdido no es simplemente un recorrido iniciático que conduce al descubrimiento de una vocación salvadora (que sería, en fin, un autodescubrimiento), punto final de un camino de (auto)conocimiento. Es más bien la fidelidad a un gesto que après coup destotaliza ese camino y lo convierte en la coherencia de un trayecto infinito, del que sólo la creación artística puede dar cuenta. La obra de arte -pero también su lectura- queda abierta a la invención.

\section{Por el camino de la fidelidad al acontecimiento (inestética(5) )}

En busca del tiempo perdido se va encaminando hacia una decisión (escribir) que permite repensar el camino recorrido transformándolo en un despliegue infinito pues la creación no tiene límites- de posibilidades. El momento capital de la novela (el nacimiento de una "vocación"), que constituye justamente su culminación, instala la posibilidad de un nuevo despliegue. Esta redimensión del pasado nos ubica en el nuevo tiempo creado-recuperado por el arte, a través de la escritura de la obra literaria.

A partir del "acontecimiento Proust" encontramos que Proust nos impone leer En busca del tiempo perdido al menos dos veces. La primera, simple o ingenua, sigue el relato de una serie de semblanzas y experiencias de vida en el que el transcurso del tiempo es el fondo homogéneo de la trama. Los saltos temporales refieren o actualizan recuerdos -que han afectado al héroe-narrador de diversas formas- en un plano sólo evocativo. La dicha, la nostalgia o el dolor que el pasado reflotado trae al presente absoluto del narrador se agota, o se colma, en la presentificación del hecho. Son sólo recuerdos. La segunda lectura permite recomponer el camino de la lectura inicial cambiando no sólo de manera completa el estatuto de los recuerdos sino también, y fundamentalmente, el estatuto del tiempo del narrador. La memoria involuntaria será entonces mucho más que una reminiscencia casual que anima la nostalgia y se agota en el sentimiento del pasado perdido.

La reiterada prospectiva "como se verá más adelante", que en diversos pasajes de la obra anuncia que algo significativo para la comprensión del conjunto de la trama habrá de ocurrir, no es el simple anticipo que puede hacer un narrador que recuerda su pasado en el relato. Es la señal de que la segunda lectura es inevitable para que la recomposición del tiempo a partir del arte (es decir, de la decisión creativa del artista) pueda efectuarse. La presentación narrativa del efecto que produce el sabor de la magdalena -por caso típico- es paradigmática: se anuncia al lector que recién con lo que advenga "más adelante" se podrá comprender la verdadera dimensión de este suceso. El autor ha decidido que ese hecho es crucial para el desenvolvimiento de la trama (y nos lo ha hecho saber a través de la voz del narrador), pero el lector nada puede saber entonces. Quizá sospeche que se trata de una clave para la recuperación del tiempo pero, por el momento, debe avanzar con su lectura ingenua. 
Cualquier segunda lectura es, por cierto, distinta de la primera en la medida en que ya se conoce el final. Pero la segunda lectura a que obliga Proust rompe con la mera superposición y afinamiento de las lecturas sucesivas. No se relee a la luz de los signos interpretados por el narrador, sino con la obra de arte (su irrupción) redefiniendo el libro.

El acontecimiento genera un tiempo propio. El tiempo "recobrado" es entonces la construcción artística de otro tiempo que acomoda, de una manera inédita, el tiempo cronológico transcurrido (6). El tiempo recobrado es "recobrado" en primera instancia por el artista, que desarrolla una actividad consecuente con aquello que transfiguró su destino. Es él quien quiebra la condena de la temporalidad y se abre, en su obra, a la eternidad. Pero también puede ser un tiempo recobrado por el lector si participa del mismo acontecimiento, es decir, si la recomposición del tiempo que cruza la obra lo involucra de tal manera que pueda redimensionar su propio tiempo. La obra habrá producido, en fin, un antes y un después en alguien.

\section{Resignificación del sentido educativo de En busca del tiempo perdido}

¿En qué sentido podríamos continuar afirmando que En busca del tiempo perdido es una novela educativa? Quizá, en la manera de sostenerse en el punto medular de los trayectos de formación: la constitución de una subjetividad. En función de lo expresado hasta aquí podremos decir que hay un sujeto Proust enlazado al acontecimiento Proust, pero ¿quién es específicamente ese sujeto? En el acontecimiento Proust convergen tres planos: el relato del héroe-narrador (que llega al punto culminante de una decisión), la vida del autor-escritor (que culmina una decisión) y la mirada del lector (que culmina una lectura). Hemos señalado el significado del cruce de los dos primeros en tanto creación de un tiempo. Pero ese cruce sólo puede tener sentido si hay un lector, y ese lector -si se relaciona con la obra afectado por el acontecimiento- compartirá la misma clave de recomposición de un tiempo. Es decir, volverá sobre la obra para recobrarla en la misma medida en que rehace su propio tiempo. Hay, entonces, tres niveles de subjetividad, en concordancia con los tres planos mencionados. Para ajustar el concepto, siguiendo a Badiou llamaremos subjetivación al proceso por el cual se es fiel a lo que la decisión (el acontecimiento) implica; esto supone "moverse en la situación que este acontecimiento ha suplementado, pensando (y todo pensamiento es una práctica, una puesta a prueba) la situación 'según' el acontecimiento. Lo que obliga a inventar una nueva manera de ser y de actuar en la situación, ya que el acontecimiento estaba fuera de todas las leyes regulares de esa situación." (BADIOU, 1994, p. 48). En sentido estricto, habría un solo sujeto: Marcel Proust, quien materializó una ruptura definitiva con su situación anterior escribiendo En busca del tiempo perdido. Pero el desafío de su obra -y por esto es una obra maestra- es poder ser completada por una lectura creadora que comparta el mismo desafío de su escritura. Concretar esta posibilidad entraña una profunda autoexploración y un importante autoaprendizaje. La tarea de escribir que deja pendiente el héroe de la novela (que deberá volver sobre su propio trayecto) será suplementada por el lector, que también deberá volver sobre su propio trayecto. 
En El tiempo recobrado Proust invita a pensar En busca del tiempo perdido como una singularidad que podría significar, tal vez, un pequeño (o gran) acontecimiento en la propia formación / transformación del lector. Esta apuesta a la libertad y a la creatividad es mucho más que un guiño cómplice para quien llegó hasta esas últimas páginas. Es la culminación coherente del trayecto que recupera el tiempo en la realización de una obra de arte. Y es un inicio para el lector cómplice, que queda expuesto a su propio desafío.

En busca del tiempo perdido alcanza el límite de la novela educativa porque desborda los esquemas lineal y metafísico que mencionamos al comienzo. El "aprendizaje" que está en juego no concluye necesariamente en una integración más armónica al mundo ni sigue una dirección privilegiada. Ni siquiera podemos decir que concluya, ya que la vuelta sobre sí es una tarea abierta para todos. Tampoco la obra desarrolla una esencia o despliega un "ya ahí" que hay que develar. Lo que habría de ser descubierto es reemplazado por lo que habrá de ser inventado. Lo que habría que desarrollar es transformado en lo que se habrá de crear.

\section{Epílogo}

Sostuvimos que el acontecimiento Proust quedaba definido en las últimas páginas de El tiempo recobrado. Justamente, en el momento en que el héroe-narrador decide iniciar su obra, que es justamente el momento en que culmina la obra maestra de Proust y, justamente también, el momento en que el lector concluye la lectura y queda abierto al desafío de crear, frente a ella, su propia mirada de sí. El camino que se cierra, se abre. El largo aprendizaje culmina en un punto de partida. Es un final porque la decisión de escribir cierra un libro y una vida; pero es un comienzo porque la obra de arte no sólo eterniza un relato y una vida sino que transfigura el tiempo del propio lector, que queda expuesto ahora a una relación singular con un libro que se vuelve sobre sí y a una mirada personal que también se vuelve sobre sí.

Hay un camino, pero no es un camino ya trazado. La libertad y el azar de los encuentros van a la par de la coherencia con que nos sostenemos en nuestras decisiones frente a ellos (en la lectura o en la vida). Es la forma de construir el camino propio y de constituirnos, quizá, en sujetos.

\section{Bibliografía}

BADIOU, Alain. "La Ética". Acontecimiento (número especial), IV, 8, 1994, p. 1193.

BADIOU, Alain. Petit manuel d'inesthétique. Paris: Seuil, 1998 
DELEUZE, Gilles. Proust y los signos. Barcelona: Anagrama, 1995

PROUST, Marcel. À la recherche du temps perdu (en un volumen, bajo dirección de J.-Y. Tadié). Paris: Gallimard, 1999. (Trad. cast.: En busca del tiempo perdido (en siete volúmenes). Madrid: Alianza, 1990/1996)

RICCEUR, Paul. Tiempo y narración II. México: Siglo XXI, 1998.

(1) Nuestra lectura difiere, además, de la que hace también cierta crítica biográfica que ve a Proust teorizando sobre arte en aquellos pasajes en los que el héroe habla de las experiencias de su propia memoria involuntaria y explica el por qué de su abrupta sensación de felicidad ante ciertos sucesos. Seguir esta dirección no nos llevaría mucho más allá de una suerte de platonismo ingenuo, que en cada fulgor de memoria involuntaria vincularía un yo puro con una esencia verdadera de las cosas, en un instante fuera del tiempo. Una cosa es lo que puede decir un personaje de ficción y otra muy distinta es pensar el conjunto del relato como una obra de arte con claves que trascienden al propio autor. En este sentido, es importante resistir a la tentación de superponer linealmente la voz del héroe o del narrador, y la voz de Proust, quien, de manera sesgada, introduciría en la novela su propia teoría del arte a la luz de la cual habría que comprender En busca del tiempo perdido . La misma novela algo nos dice al respecto: "Una obra en la que hay teorías es como un objeto en el que se deja la marca del precio." (PROUST, VII, 1996, p. 230)

(2) La justificación de la denominación "acontecimiento Proust" involucra dos perspectivas: por un lado, la que refiere el cruce que puede establecerse entre la obra y la vida del autor para la elucidación de la vinculación entre la obra de arte y el tiempo, y, por otro, la que pondera el impacto de En busca del tiempo perdido en el conjunto de la literatura francesa y mundial (como límite que marca un antes y un después, tanto en la estructuración narrativa o la consideración artística del tiempo como en la construcción de la novela educativa o de formación). En este trabajo me referiré sólo a la primera perspectiva.

(3) La otra cara de la decisión frente al recuerdo que llevan adelante el héroenarrador y Proust lo constituye la actitud emotiva de Swann al escuchar el septeto de Vinteuil, esa minúscula frase que evoca su amor tortuoso por Odette. En este caso se trata meramente del recuerdo que agota su desafío en la rememoración nostálgica y sensible de algo pasado de manera irremediable. Swann no encontrará una verdad del amor como tampoco lo hará con el arte, ya que, por ejemplo, jamás terminará de escribir su estudio sobre Vermeer.

(4) Para Ricour, la salvación venía enseguida, a través de los signos premonitorios de la gran revelación sobre el arte.

(5) Voy a emplear este término siguiendo el sentido que le atribuye Alain Badiou: "Llamo 'inestética' a una relación de la filosofía con el arte que plantea que si bien 
el arte produce verdades por sí mismo, no por ello pretende hacer de él un objeto para la filosofía. Frente a la especulación estética, la inestética describe los efectos estrictamente intrafilosóficos producidos por la existencia independiente de algunas obras de arte." (BADIOU, 1998, p. 7).

(6) Es revelador que a lo largo de la obra no aparezcan fechas. Sólo algunos datos históricos del "mundo real" permiten situar ciertos pasajes y poder establecer algunos paralelos con la "realidad". La cronología pasa a un segundo plano insignificante. La obra es creación de su propio tiempo. 